https://doi.org/10.22319/rmcp.v11i1.4998

Artículo

\title{
Relación genética, formación de biopelículas, movilidad y virulencia de Escherichia coli aislada de mastitis bovina
}

\author{
Alejandro Sergio Cruz-Soto ${ }^{a}$ \\ Valentín Toro-Castillo ${ }^{\mathrm{a}}$ \\ Cristián Omar Munguía-Magdaleno a \\ José Emmanuel Torres-Flores ${ }^{\text {a }}$ \\ Luis Enrique Flores-Pantoja ${ }^{\text {a }}$ \\ Pedro Damián Loeza-Lara ${ }^{\text {a }}$ \\ Rafael Jiménez-Mejía ${ }^{a *}$
}

${ }^{a}$ Universidad de La Ciénega del Estado de Michoacán de Ocampo. Genómica Alimentaria. Avenida Universidad No. 3000. Col. Lomas de la Universidad, 59103, Sahuayo, Michoacán, México.

*Autor de correspondencia: rjimenez@ucienegam.edu.mx

\section{Resumen:}

Escherichia coli es una de las bacterias ambientales que frecuentemente se ha visto implicada en infecciones de la glándula mamaria bovina. Aunque se desconocen los factores de virulencia específicos involucrados en dicho proceso, se ha observado que las bacterias formadoras de biopelículas se asocian con infecciones persistentes. De igual forma se ha planteado que las bacterias móviles pueden ser más patógenas. El propósito del trabajo fue analizar la relación genética, capacidad de formación de biopelículas y movilidad de $E$. coli aislada de casos de mastitis bovina, así como la virulencia in vivo de aislados representativos. El $67.7 \%$ de las bacterias pertenece al grupo filogenético A, el 17.6 \% al grupo B1 y el 14.7 $\%$ al D. El estudio de la relación genética mediante $(\mathrm{GTG})_{5}$ reveló que solo dos bacterias son idénticas genéticamente, el resto se organizaron en siete grupos distintos con $70 \%$ de 
similitud. El $76.5 \%$ de las bacterias fue capaz de formar biopelículas de forma fuerte, moderada o débil. Además, los genes $\operatorname{csg}$ A y fimA se detectaron en el $52.9 \%$ de las bacterias formadoras de biopelículas. El análisis de movilidad mostró que el $70.6 \%$ fue móvil. Mientras que, el análisis de patogenicidad en larvas de Galleria mellonella reveló que bacterias formadoras de películas y móviles fueron capaces de matar un mayor número de larvas a las $24 \mathrm{~h}$ que las no formadoras. Los resultados indican que las E. coli causantes de mastitis bovina son muy diversas y pertenecen principalmente al grupo filogenético A y que las formadoras de biopelículas y móviles son más patógenas.

Palabras clave: E. coli, Mastitis bovina, Diversidad, Biopelículas, Virulencia.

Recibido: $24 / 07 / 2018$

Aceptado: 16/01/2019

\section{Introducción}

La mastitis bovina es la principal causa de pérdidas económicas a nivel mundial debido a la disminución en la producción de leche, costos de tratamiento, descarte temprano de ganado, entre otros ${ }^{(1)}$. Uno de los principales patógenos ambientales causante de mastitis bovina es E. coli, cuyas infecciones pueden ser desde moderadas hasta severas ${ }^{(2,3)}$. Aunque a la fecha no se han logrado determinar los factores de virulencia específicos de las E. coli asociadas a mastitis bovina, se ha propuesto que éstas pueden formar parte de un nuevo patotipo denominado Mammary Pathogenic E. coli $(\mathrm{MPEC})^{(4)}$. De acuerdo con esto último, estudios más recientes a nivel genómico han revelado la presencia de grupos de genes que codifican para sistemas se secreción tipo VI, biosíntesis de lipopolisacáridos, formación de biopelículas y sistemas de captación de hierro, característicos de las $E$. coli asociadas a mastitis bovina ${ }^{(5-}$ ${ }^{8)}$. Sin embargo, otros autores sugieren que no hay evidencia suficiente de que las $E$. coli causantes de mastitis pertenecen a un patotipo particular ${ }^{(9)}$.

Diversos análisis filogenéticos de $E$. coli han permitido clasificarlas en cuatro grupos principales A, B1, B2 y D, en donde las bacterias comensales no patógenas pertenecen principalmente a los grupos A y B1, aunque estos filogrupos también incluyen patógenos importantes. Mientras al grupo B2 y en menor proporción al D, pertenecen las bacterias asociadas con infecciones extra-intestinales ${ }^{(9,10)}$. Para el caso de $E$. coli causantes de mastitis bovina se ha observado que pertenecen principalmente a los grupos filogenéticos A y $\mathrm{B} 1^{(11,12,13)}$. Además, análisis genéticos y genómicos han revelado que las $E$. coli asociadas a mastitis bovina son muy diversas. En este sentido se ha reportado que las E. coli asociadas a mastitis bovina tanto persistente como transitoria, muestran diversidad fenotípica y 
genotípica $^{(14)}$. Asimismo, el análisis a nivel genómico de diversos aislados de E. coli, causantes de mastitis bovina y comensales, ha mostrado en ninguno de los casos las bacterias pueden clasificarse en un grupo filogenético en particular, sino que al parecer en ambos casos se han originado de diferentes linajes ${ }^{(9)}$.

La habilidad para colonizar e invadir el epitelio mamario bovino ayuda a las bacterias a evadir la respuesta inmune e infectar de forma persistente. En este sentido, se ha demostrado que $E$. coli causante de mastitis persistente invade células epiteliales mamarias en forma eficiente, aunque los mecanismos empleados para tal fin no se conocen con precisión, pero se observó que las bacterias que muestran mayor movilidad tienen mayor virulencia ${ }^{(15)}$. De igual forma, la matriz polimérica extracelular de las bacterias formadoras de biopelículas las hace más resistentes a diversas sustancias químicas con actividad antimicrobiana producidas por las células, además de que las protege del sistema inmune innato ${ }^{(16,17)}$.

Generalmente, para el estudio de la virulencia bacteriana se utilizan diversos modelos animales; sin embargo, muchos de esos modelos son costosos y presentan algunos problemas éticos. Por lo cual, en épocas recientes, uno de los modelos que ha tomado importancia son las larvas del insecto Galleria mellonella, en las que se ha analizado la virulencia de bacterias patógenas, tanto Gram positivas como negativas, así como hongos ${ }^{(18,19)}$. Por ejemplo, se ha observado que G. mellonella es un modelo adecuado para el estudio de variantes patógenas de E. coli tanto intestinales como extraintestinales ${ }^{(20,21,22)}$.

El objetivo del presente trabajo fue estudiar la diversidad genética, determinar los grupos filogenéticos, la capacidad de formación de biopelículas y movilidad de E. coli aisladas de casos de mastitis bovina subclínica, así como evaluar la virulencia de aislados representativos in vivo usando como modelo de estudio larvas de G. mellonella.

\section{Material y métodos}

\section{Preparación de extractos de ADN y determinación del grupo filogenético}

Se estudiaron 34 E. coli resistentes a antibióticos, que fueron aisladas de casos de mastitis bovina subclínica en el occidente del estado de Michoacán, México, y las cuales fueron descritas previamente ${ }^{(23)}$. A partir de estos aislados se prepararon extractos totales de ADN de acuerdo a lo descrito en la literatura ${ }^{(24)}$. Para la determinación del grupo filogenético al que pertenecen las $E$. coli se siguió el esquema descrito en la literatura ${ }^{(10)}$. Los primers utilizados para la amplificación de los fragmentos fueron: ChuA.1 (5'GACGAACCAACGGTCAGGAT-3') y ChuA.2 (5'-TGCCGCCAGTACCAAAGACA-3'), YjaA.1 (5'-TGAAGTGTCAGGAGACGCTG-3') y YjaA.2 (5'ATGGAGAATGCGTTCCTCAAC-3') y TspE4C2.1 (5'GAGTAATGTCGGGGCATTCA-3') y TspE4C2.2 (5'-CGCGCCAACAAAGTATTACG- 
$\left.3^{\prime}\right)$. Las reacciones de PCR se realizaron en un volumen de $25 \mu 1$ conteniendo: $1 \mathrm{X}$ PCR Master mix (Promega, Madison, WI, USA), $1 \mu \mathrm{M}$ de cada primer y $2 \mu 1$ de extracto de ADN bacteriano (50 ng). La amplificación de los fragmentos se llevó a cabo en un termociclador C1000 (Bio-Rad, México, DF, México) en las siguientes condiciones: un ciclo inicial de desnaturalización inicial a $94{ }^{\circ} \mathrm{C}$ por $5 \mathrm{~min}$, seguido de 30 ciclos en las siguientes condiciones; desnaturalización a $94{ }^{\circ} \mathrm{C}$ por $30 \mathrm{~s}$, alineamiento a $55^{\circ} \mathrm{C}$ por $30 \mathrm{~s}$ y extensión a $72{ }^{\circ} \mathrm{C}$ por $30 \mathrm{~s}$. La amplificación se terminó con un ciclo de extensión a $72{ }^{\circ} \mathrm{C}$ durante 5 min. Los productos amplificados se separaron en geles de agarosa al $1.5 \%$ y se visualizaron en un fotodocumentador Universal Hood II (Bio-Rad).

\section{Producción de biopelículas}

La producción de biopelículas se realizó de acuerdo a la literatura ${ }^{(25)}$ con algunas modificaciones como se describe a continuación. Las bacterias se sembraron en cajas Petri con agar soya tripticasa (AST, BD, México, DF, México), a partir de dichos cultivos se inocularon tubos con $2 \mathrm{ml}$ de caldo soya tripticasa (CST) adicionado de $0.25 \%$ de glucosa, se incubaron toda la noche a $37{ }^{\circ} \mathrm{C}$ con agitación constante. Al día siguiente los cultivos se diluyeron hasta igualar con el tubo 0.5 de la escala de MacFarland en TSB con $0.25 \%$ de glucosa. De la dilución bacteriana se depositaron $200 \mu \mathrm{l}$ por triplicado en placas de Elisa de 96 pozos y se crecieron por $24 \mathrm{~h}$ a $37^{\circ} \mathrm{C}$ sin agitación. Como control negativo se usó medio de cultivo sin inocular y como control positivo se utilizó la bacteria formadora de biopelículas Pseudomonas aeruginosa ATCC 27853. Se descartó el cultivo bacteriano y los pozos de la placa se lavaron tres veces con solución salina estéril, para la fijación de las células la placa se dejó secar a $60{ }^{\circ} \mathrm{C}$ por $1 \mathrm{~h}$. Posteriormente, se adicionaron $200 \mu \mathrm{l}$ de cristal violeta al $1 \%$ y se dejó a temperatura ambiente por 20 min, se lavó la placa con agua corriente hasta que no se observó desprendimiento de color y se dejó secar a temperatura ambiente. A cada pozo de la placa se le adicionaron $200 \mu 1$ de etanol al 96\%, se agitó para solubilizar el cristal violeta, el sobrenadante se transfirió a un tubo de microcentrífuga y se repitió el proceso, el volumen del tubo se llevó a $1 \mathrm{ml}$ y se midió la densidad óptica a $570 \mathrm{~nm}$ (D.O.) en un espectrofotómetro SmartSpec Plus (Bio-Rad). El ensayo se repitió cuatro veces por triplicado y con los datos obtenidos se calculó el promedio de la D.O. De igual forma se calculó la densidad óptica de corte (D.O.c.), para lo cual se tomó como base el promedio de la D.O. del control negativo más tres veces su desviación estándar, obteniéndose un valor de 0.22 . La clasificación de las bacterias formadoras de biopelículas se realizó como sigue: formadoras fuertes D.O $>4$ xD.O.c., moderadas 2 xD.O.c. $<$ D. $0 \leq 4$ xD.O.c., débiles D.O.c. $<$ D.O. $\leq 2 x D . O . c$. y negativas D.O. $\leq$ D.O.c. ${ }^{(25)}$. 


\section{Detección de genes asociados a la formación de biopelículas}

Se analizó mediante PCR la presencia de dos genes asociados con la formación de biopelículas, fimA (subunidad principal de la fimbria tipo I) y $\operatorname{csg} A$ (subunidad principal de la fimbria curli). Para lo cual se amplificó un fragmento de 119 pb de fimA con fimA-F (5'CTCTGGCAATCGTTGTTCTGTCG-3') y fimA-R (5'GCAAGCGGCGTTAACAACTTCC-3') y de 178 pb de $\operatorname{csg} A$ con $\operatorname{csg} A-F$ (5'GATCTGACCCAACGTGGCTTCG-3') y csgA-R (5'-GATGAGCGGTCGCGTTGTTA CC-3' ${ }^{(26)}$. Las reacciones se realizaron en $25 \mu 1$ conteniendo $1 X$ PCR Master mix (Promega), $1 \mu \mathrm{M}$ de cada primer, $2 \mu \mathrm{l}$ de extracto total de ADN. Las condiciones utilizadas fueron las siguientes: un ciclo inicial de desnaturalización a $95^{\circ} \mathrm{C}$ por $5 \mathrm{~min}$, seguido de 30 ciclos a 94 ${ }^{\circ} \mathrm{C}$ por $30 \mathrm{~s}, 55^{\circ} \mathrm{C}$ por $30 \mathrm{~s} \mathrm{y} 72{ }^{\circ} \mathrm{C}$ por $30 \mathrm{~s}$, las reacciones se terminaron con un ciclo de extensión a $72{ }^{\circ} \mathrm{C}$ por $10 \mathrm{~min}$. Los productos amplificados se separaron en geles de agarosa al $2 \%$ y se visualizaron como se describió anteriormente.

\section{Determinación de la movilidad tipo "swarming"}

El análisis de movilidad bacteriana se realizó siguiendo el protocolo ya descrito ${ }^{(15)}$. Para la movilidad tipo swarming los cultivos se crecieron toda la noche en caldo LB (Lysogeny Broth). Posteriormente se depositaron $5 \mu \mathrm{l}$ en placas con agar swarming (LB con agar al $0.5 \%$ ) adicionado con $0.5 \%$ de glucosa. Las bacterias se incubaron por $12 \mathrm{~h}$ a $37{ }^{\circ} \mathrm{C}$. Posteriormente se midió el diámetro del desplazamiento bacteriano, las determinaciones se repitieron al menos tres veces y con los datos obtenidos se calculó el promedio.

\section{Rep-PCR de $E$. coli causante de mastitis bovina}

Para el análisis de la diversidad genética se purificó ADN genómico de acuerdo a protocolos estándar ${ }^{(27)}$, con el DNA purificado se realizaron amplificaciones por PCR en $25 \mu 1$ de mezcla de reacción con los siguientes componentes: $12.5 \mu \mathrm{l}$ de $2 \mathrm{X}$ Master mix (Promega), $3 \mathrm{mM}$ de $\mathrm{MgCl}_{2}, 5 \%$ de DMSO, $0.16 \mu \mathrm{g} / \mu \mathrm{l}$ de albumina de suero bovino, $100 \mathrm{ng}$ de ADN y $2 \mu \mathrm{M}$ del primer (GTG) (5'-GTGGTGGTGGTGGTG-3'). La amplificación se realizó en un termociclador C-1000 (Bio-Rad) en las siguientes condiciones: un ciclo de desnaturalización inicial a $95{ }^{\circ} \mathrm{C}$ durante 2 min, seguido de 30 ciclos a las siguientes condiciones; desnaturalización $\left(94{ }^{\circ} \mathrm{C} / 3 \mathrm{~s} \mathrm{y} 92^{\circ} \mathrm{C} / 30 \mathrm{~s}\right)$, alineamiento $\left(40{ }^{\circ} \mathrm{C} / 1 \mathrm{~min}\right)$, extensión $\left(65^{\circ} \mathrm{C} / 8\right.$ min) y se finalizó con un ciclo de extensión a $65{ }^{\circ} \mathrm{C}$ durante $8 \mathrm{~min}^{(28)}$. Los productos amplificados se separaron en geles de agarosa al $1.5 \%$ y se visualizaron en un fotodocumentador Universal Hood II (Bio-Rad).

Para el análisis de los patrones de bandas obtenidos se usó el software GelJ versión $2^{(29)}$. El tamaño de las bandas fue normalizado usando como estándar de referencia el marcador $1 \mathrm{~kb}$ 
DNA ladder (Promega), que tiene fragmentos entre 250 y 10,000 pb. Los coeficientes de similitud fueron generados por el método de Dice con $2 \%$ de tolerancia entre los carriles y el dendrograma se construyó usando el método UPGMA.

\section{Virulencia en Galleria mellonella}

Se analizó la virulencia in vivo de bacterias representativas que mostraron los mayores índices de formación de biopelículas, así como no formadoras en larvas de G. mellonella; para lo cual, se utilizaron larvas de 150 a $200 \mathrm{mg}$, libres de daño aparente y sin melanización (manchas necróticas) (Petmmal, Cuautitlán Izcalli, México). Las larvas se almacenaron en a $30{ }^{\circ} \mathrm{C}$ en obscuridad hasta su uso. Para los ensayos de infección se utilizaron cultivos bacterianos crecidos en caldo LB hasta la fase exponencial media de crecimiento (D.O. 600 $\mathrm{nm}=0.5$ ), se centrifugaron a 12,000 rpm/min, se lavaron dos veces con $1 \mathrm{ml} \mathrm{de} \mathrm{MgSO}_{4} 10$ $\mathrm{mM}$, al final las bacterias se re-suspendieron en $1 \mathrm{ml}$ de $\mathrm{MgSO}_{4} 10 \mathrm{mM}$. A partir de esta suspensión celular, se realizaron diluciones seriales hasta obtener una concentración bacteriana de aproximadamente $1 \times 10^{5} \mathrm{UFC} / \mathrm{ml}$, lo cual fue confirmado mediante el conteo de UFC en agar LB.

Para cada una de las bacterias a estudiar se utilizaron 10 larvas de G. mellonella, a las cuales se les inyectaron $10 \mu \mathrm{l}$ de la suspensión bacteriana $\left(1 \times 10^{5} \mathrm{UFC} / \mathrm{ml}\right)$ en la última pro-pierna, con una jeringa de insulina con aguja calibre 29G. Como controles negativos se inyectaron 10 larvas con $\mathrm{MgSO}_{4} 10 \mathrm{mM}$ sin bacterias y 10 más sin inocular. Las larvas, tanto inoculadas como no inoculadas se colocaron en cajas Petri estériles y se incubaron a $30^{\circ} \mathrm{C}$ en obscuridad por $96 \mathrm{~h}$. Se determinó el porcentaje de sobrevivencia a las 24, 48, 72 y $96 \mathrm{~h}$, se registraron como muertas aquellas larvas que no respondieron al tacto ${ }^{(21)}$. Los ensayos de infección con cada bacteria se repitieron al menos dos veces de forma independiente.

\section{Resultados}

\section{Grupos filogenéticos y relación genética de $E$. coli asociada a mastitis bovina}

De acuerdo a los resultados obtenidos de la amplificación de los fragmentos chuA (279 pb), yjaA (211 pb) y TspE4.C2 (152 pb) (Figura 1), las 34 E. coli asociadas a mastitis bovina se clasificaron en tres grupos filogenéticos. El $67.7 \%$ (23 aislados) pertenece al grupo A, el $17.6 \%$ corresponde al grupo B1 (6 aislado) y el restante $14.7 \%$ (5 aislados) corresponde al D (Figura 2B). 
Figura 1: Geles de agarosa de los resultados positivos y negativos representativos de la amplificación por PCR de: A) chuA (279 pb), B) yjaA (211 pb) y, C) TspE.C2 (152 pb)
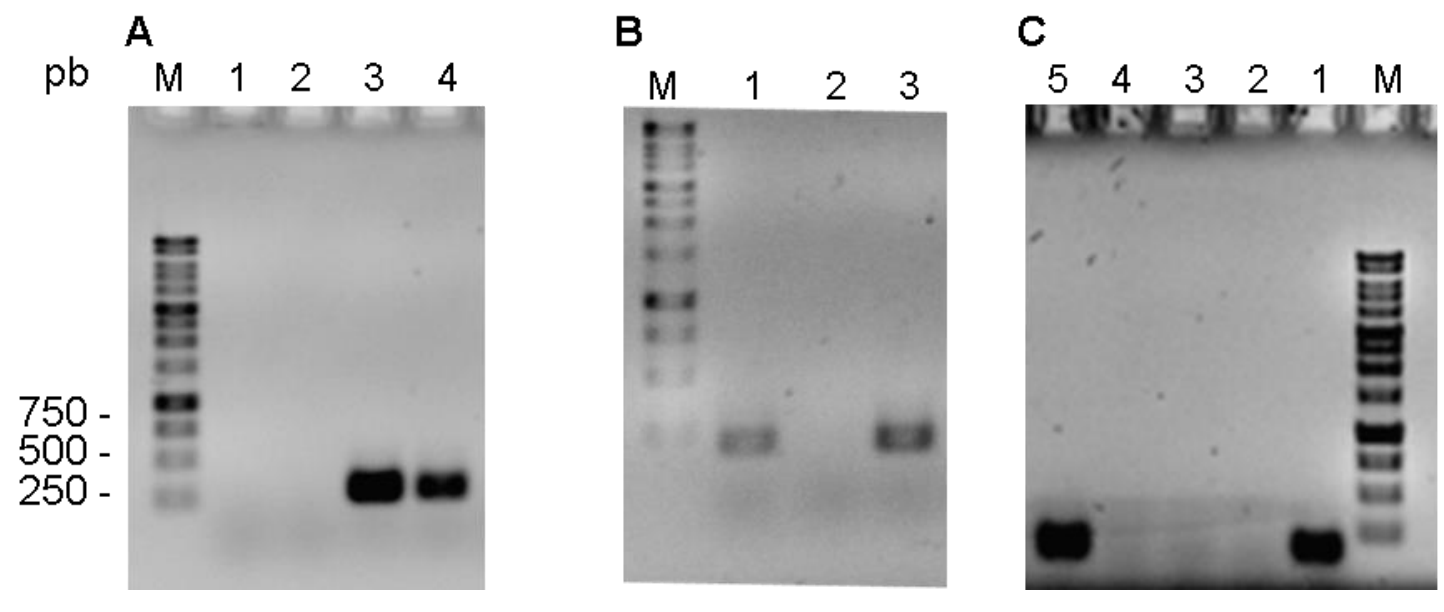

El análisis de relación genética mediante rep-PCR con el oligonucleótido (GTG)5 arrojó 32 patrones distintos de entre 7 y 21 bandas, con tamaños que oscilaron de 250 a 5,000 pb (Figura 2). El dendrograma generado a partir de los patrones de bandas usando el coeficiente de similitud de Dice por el método de UPGMA, indica que la similitud más baja entre los aislados fue de $58 \%$, mientras que la mayor similitud observada fue del $100 \%$ en dos aislados. También se puede apreciar que considerando una similitud genética del $70 \%$ (línea punteada) se identificaron 7 grupos de bacterias, de los cuales el grupo VII fue el más grande con $22(64.7 \%)$ aislados, el grupo III con 4 (11.8\%), el grupo VI con $3(8.8 \%)$ bacterias, el grupo I con $2(5.8 \%)$ y los grupos II, IV y V con un solo aislado $(2.9 \%)$, respectivamente (Figura 3).

Figura 2: Gel de agarosa de la separación de los productos amplificados por (GTG) ${ }_{5}-\mathrm{PCR}$, se indica el tamaño en pares de bases de algunas bandas del marcador de $1 \mathrm{~kb}$

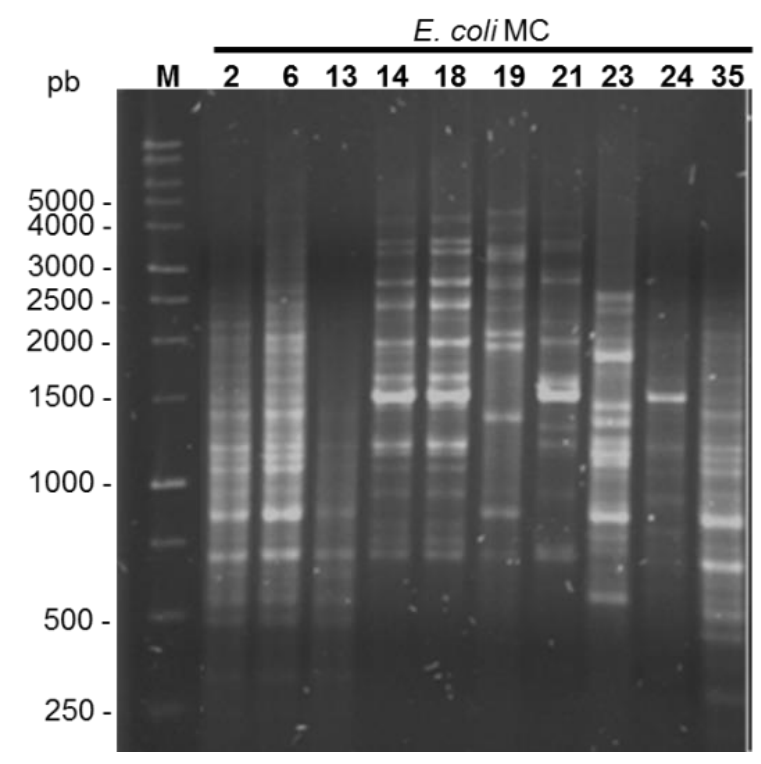


Figura 3: Agrupamiento de los patrones de bandas obtenidos en 34 E. coli asociadas a mastitis bovina, basado en el coeficiente de similitud de Dice generado mediante UPGMA
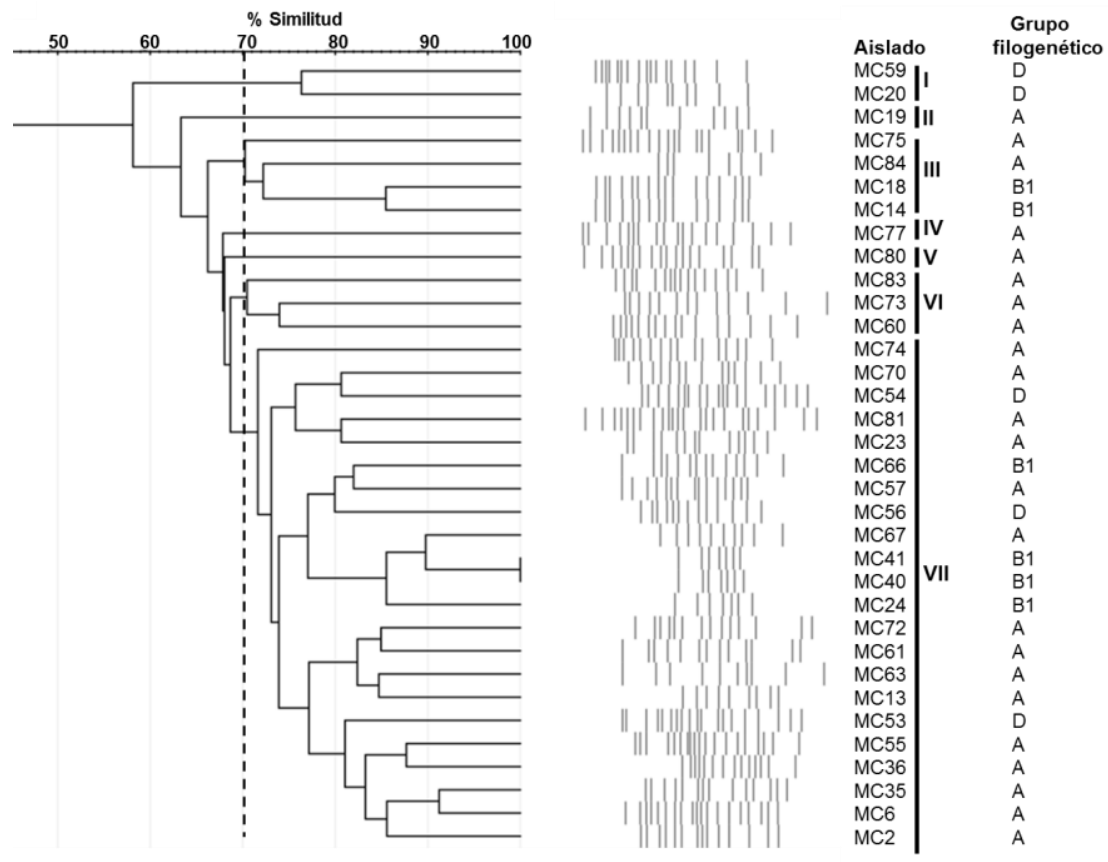

\section{Movilidad, formación de biopelículas y detección de genes asociados}

El análisis de la movilidad de las 34 E. coli, reveló que 10 no fueron móviles (-) y 24 mostraron movilidad. De éstas últimas de acuerdo al diámetro del desplazamiento 12 se consideraron poco móviles $(+), 6$ con movimiento moderado $(++)$ y 6 fueron muy móviles $(+++)$ (Figura 4 y Cuadro 1$)$.

Figura 4: Resultados representativos de movilidad tipo "swarming". A) No móvil, B) Poco móvil, C) Moderadamente móvil, D) Muy móvil
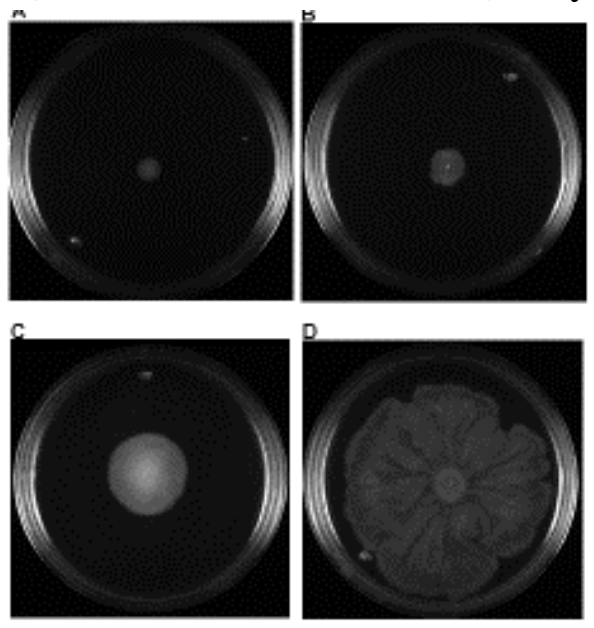
Cuadro 1: Movilidad, formación de biopelículas y frecuencia de genes asociados a la formación de biopelículas de 34 aislados de E. coli provenientes de casos de mastitis bovina subclínica

\begin{tabular}{|c|c|c|c|}
\hline E. coli & Movilidad $^{\mathbf{a}}$ & Biopelícula $^{b}$ & $\begin{array}{c}\text { Genotipo } \\
\operatorname{csg} A / \operatorname{fim} A \\
\end{array}$ \\
\hline MC75 & +++ & $\mathrm{D}$ & $+/+$ \\
\hline MC80 & + & $\mathrm{N}$ & $+/+$ \\
\hline MC81 & + & $\mathrm{D}$ & $+/+$ \\
\hline MC83 & + & $\mathrm{N}$ & $+/+$ \\
\hline MC13 & - & $\mathrm{F}$ & $-/-$ \\
\hline MC14 & - & $\mathrm{D}$ & $+/+$ \\
\hline MC72 & +++ & M & $+/+$ \\
\hline MC19 & ++ & $\mathrm{F}$ & $-/+$ \\
\hline MC40 & +++ & $\mathrm{D}$ & $+/+$ \\
\hline MC41 & + & $\mathrm{N}$ & $+/+$ \\
\hline MC59 & - & $\mathrm{D}$ & $-/-$ \\
\hline MC73 & + & M & $-/-$ \\
\hline MC66 & - & $\mathrm{D}$ & $+/+$ \\
\hline MC2 & - & $\mathrm{F}$ & $-/-$ \\
\hline MC6 & + & $\mathrm{F}$ & $-/-$ \\
\hline MC35 & ++ & $\mathrm{F}$ & $-/+$ \\
\hline MC36 & + & $\mathrm{F}$ & $-/+$ \\
\hline MC84 & - & $\mathrm{D}$ & $-/-$ \\
\hline MC24 & + & $\mathrm{D}$ & $+/+$ \\
\hline MC56 & ++ & $\mathrm{D}$ & $+/+$ \\
\hline MC67 & - & $\mathrm{N}$ & $+/+$ \\
\hline MC74 & ++ & M & $-/-$ \\
\hline MC77 & ++ & $\mathrm{N}$ & $-/-$ \\
\hline MC55 & + & $\mathrm{F}$ & $-/-$ \\
\hline MC60 & + & $\mathrm{D}$ & $-/-$ \\
\hline MC54 & +++ & M & $+/+$ \\
\hline MC18 & + & $\mathrm{D}$ & $+/+$ \\
\hline MC23 & - & M & $-/+$ \\
\hline MC57 & - & M & $-/-$ \\
\hline MC53 & +++ & $\mathrm{N}$ & $+/+$ \\
\hline MC20 & + & $\mathrm{N}$ & $+/+$ \\
\hline MC70 & +++ & $\mathrm{D}$ & $+/+$ \\
\hline MC61 & ++ & $\mathrm{N}$ & $+/+$ \\
\hline MC63 & - & $\mathrm{M}$ & $-/-$ \\
\hline
\end{tabular}

a(-) no móvil, (+) poco móvil, (++) moderadamente móvil, (+++) muy móvil.

${ }^{b} \mathrm{~N}$, negativo; D, débil; $\mathrm{M}$, moderado; F, fuerte. 
Para la formación de biopelículas 26 aislados (76.5\%) formaron biopelículas en algún grado (D.O. >0.22) y las restantes $8(23.5 \%)$ no fueron formadoras (D.O. $\leq 0.22)$. Para el caso de las formadoras, siete se clasificaron como formadoras fuertes (D.O. $>0.88$ ) y moderadas (D.O. 0.45-0.88), mientras que 12 mostraron capacidad de formación débil (D.O. 0.23-0.44) (Cuadro 1). En 22 (64.7 \%) de las 34 E. coli se detectó la presencia de alguno de los dos genes $\operatorname{csg} A$ /fimA, mientras que de las 26 formadoras en 15 se detectó uno o los dos genes. También los genes $\operatorname{csg} A$ y fimA se observaron en siete aislados no formadores de biopelículas.

\section{Virulencia de $E$. coli en G. mellonella}

Con el propósito de analizar si hay diferencias en la patogénesis de los aislados de E. coli asociadas a mastitis bovina se realizaron ensayos de infección en larvas de G. mellonella con siete aislados representativos, cinco formadores fuertes de biopelículas y dos no formadores. Como se observa en la Figura 5, las bacterias formadoras de biopelículas mataron el $100 \%$ de las $G$. mellonella a las 24 h después de la infección; mientras que, con los dos aislados no formadores de biopelículas se observó una mortalidad de entre 0 y $20 \%$ a las 24 h y de 10 y $50 \%$ a las 96 h. Para el caso del control no se observaron decesos durante las 96 h que duró el experimento.

Figura 5: Virulencia en $G$. mellonella de siete aislados representativos de E. coli, los formadores de biopelículas fueron MC2, 6, 13, 19 y 35. MC41 y MC80 no fueron formadores de biopelículas. También se muestra el control negativo (C)

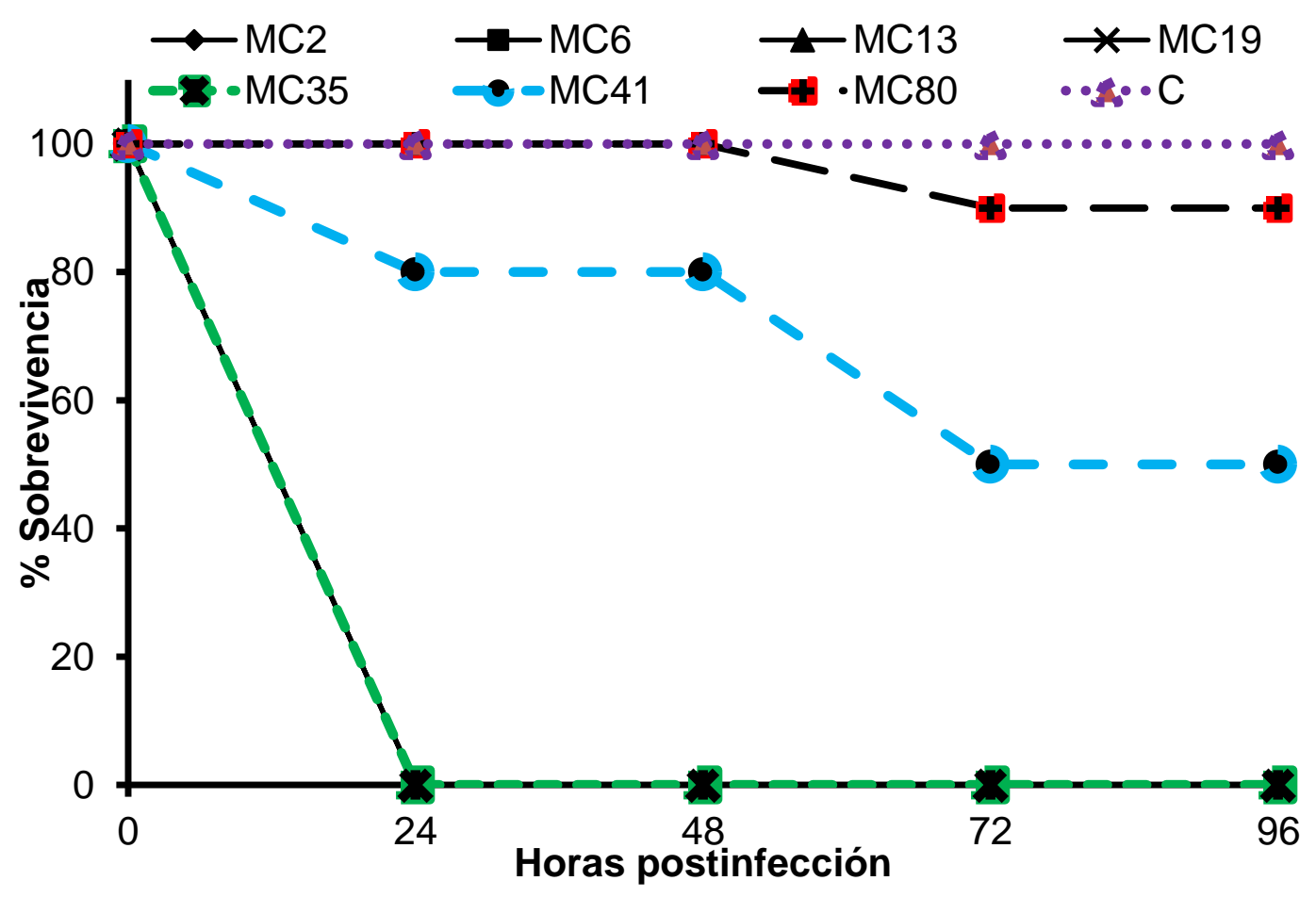




\section{Discusión}

La mastitis bovina causada por $E$. coli es una infección que puede ser desde leve hasta severa, aunque a la fecha no se han asociado factores de virulencia específicos a dichas bacterias causantes de la enfermedad $^{(11,30)}$, incluso se ha sugerido que la severidad de la infección está determinada por las características del ganado más que por los microorganismos ${ }^{(31)}$. Además, una línea de evidencia ha sugerido que las infecciones mamarias pueden ser producidas por cualquier cepa de $E$. coli ${ }^{(11)}$, mientras que otra ha mostrado que no todos los aislados de $E$. coli son capaces de producir mastitis en modelos animales ${ }^{(5)}$.

Por otro lado, se ha observado que las E. coli causantes de mastitis bovina pertenecen principalmente al grupo filogenético A, B1 y en menor proporción al grupo $\mathrm{D}^{(7)}$. De acuerdo con los reportes previos, en este trabajo se encontró que el $67.6 \%$ de las E. coli analizadas pertenecen al grupo filogenéticos A, $17.6 \%$ al B1 y $14.7 \%$ al grupo D. En este mismo sentido, en un estudio se observó que el $50 \%$ de las E. coli asociadas tanto a mastitis persistente como transitoria pertenecen al filogrupo A, $28.6 \%$ al B1 y $7.1 \%$ al grupo B2 y $\mathrm{D}$, respectivamente ${ }^{(14)}$. Otros autores han descrito que el $44.88 \%$ de las E. coli asociadas a mastitis pertenecen al filogrupo A, $38.58 \%$ al B1 y $16.53 \%$ al $\mathrm{D}^{(32)}$. Resultados similares también han sido reportados en otros trabajos ${ }^{(13,33)}$. Además, se ha observado que las $E$. coli aisladas de mastitis bovina presentan gran diversidad en serotipos, tipo de enfermedad (transitoria o persistente) y genotipo, incluso aunque pertenezcan a un mismo grupo filogenético determinado ${ }^{(3,34)}$. En este sentido, las $34 \mathrm{E}$. coli analizadas en este trabajo presentaron gran diversidad genética, solo dos de ellas mostraron patrones de bandas idénticos, las restantes presentaron similitud entre el 92 y $58 \%$. Los resultados obtenidos también indican que no hay una separación clara entre los diferentes filogrupos, lo cual indica una gran heterogeneidad entre las $E$. coli causantes de mastitis bovina en nuestra área de estudio. Otros autores también han observado gran diversidad genética en $E$. coli causantes de mastitis bovina ${ }^{(3,30,34,35)}$.

La habilidad de formar biopelículas en bacterias patógenas les confiere protección contra el sistema inmune del hospedero y resistencia a antibióticos, además de ser importante para la virulencia $^{(26)}$. En este sentido, se ha observado que las bacterias asociadas a mastitis bovina muestran un patrón variable en la formación de biopelículas ${ }^{(36)}$. Aunque en las infecciones recurrentes se ha asociado a aquellas bacterias con la capacidad de formación de biopelículas $^{(16)}$. Los resultados descritos en este trabajo muestran que $20.6 \%$ de los aislados pueden formar biopelículas de forma fuerte y moderada, mientras que $35.3 \%$ lo hace de forma débil. De forma similar en otros estudios se ha observado que E. coli asociadas a mastitis bovina son capaces de formar biopelículas de forma variable, donde $18.5 \%$ lo hace de forma fuerte, $40.7 \%$ moderada y débil ${ }^{(36)}$. En otro estudio se describió que $40 \%$ de las $E$. 
coli asociadas a mastitis bovina fue formador fuerte de biopelículas, 12 y $4 \%$ lo hicieron de forma moderada y débil, respectivamente ${ }^{(33)}$.

De las $34 \mathrm{E}$. coli analizadas, en el $52.9 \%$ se detectó la presencia de los genes $\operatorname{csg} \mathrm{A}$ y fimA, en el $11.8 \%$ solo se detectó fimA y en el restante $35.3 \%$ no se detectó ninguno de los dos. En 15 de las 26 E. coli formadoras de biopelículas se detectó la presencia de al menos uno de los genes, mientras que en siete no formadores se detectó al menos uno de los dos genes. En este sentido, ambos genes se han asociado a la formación de biopelículas, al igual que otra variedad de genes y condiciones ambientales ${ }^{(37)}$. Por lo cual, se requieren más estudios para caracterizar con más detalle los factores que afectan o promueven la formación de biopelículas en nuestra colección bacteriana. Por otro lado, se ha descrito que la formación de biopelículas varía dependiendo de la cepa, medio de cultivo, metodología y método de cuantificación. En este estudio solo se probó un medio de cultivo y una temperatura, por lo que pudiera ser que en otras condiciones las bacterias no formadoras de biopelículas y positivas para los genes $\operatorname{csg} A$ y fimA sean capaces de formar biopelículas ${ }^{(38)}$.

Otro factor importante para que las bacterias se diseminen y produzcan infecciones persistentes en el ganado es la movilidad ${ }^{(15)}$. De acuerdo con lo anterior se encontró que 70.6 $\%$ de las E. coli estudiadas fueron móviles, esto sugiere que en nuestra colección tenemos bacterias tanto de mastitis persistente como transitoria. Además, los resultados obtenidos in vivo indican que las bacterias formadoras de biopelículas mostraron mayor virulencia contra las larvas de G. mellonella en comparación con las no formadoras. Aunque se requiere más trabajo para establecer la correlación entre la patogénesis in vivo en G. mellonella con la severidad de la enfermedad causada por E. coli. Los resultados presentados en este trabajo sugieren que este organismo puede ser un modelo adecuado para analizar la patogénesis de las $E$. coli causantes de mastitis.

\section{Conclusiones e implicaciones}

Los resultados presentados en este trabajo indican que las E. coli asociadas a mastitis bovina en nuestra área de estudio son muy diversas tanto a nivel genético como fisiológico. Y que las bacterias que tienen la habilidad para formar biopelículas de forma fuerte son más patógenas que las no formadoras. La diversidad genética y fenotípica de las bacterias estudiadas indica que no hay cepa, genotipo o factor de virulencia específico asociado a la enfermedad. Sin embargo, debido a que las bacterias formadoras de biopelículas se han asociado con infecciones mamarias recurrentes y persistentes, es importante estudiar mejores estrategias para el control de las infecciones causadas por esas bacterias. Lo cual podría disminuir las pérdidas económicas asociadas con la reducción en la producción y calidad de la leche. 


\section{Agradecimientos}

Este trabajo fue apoyado por PRODEP (IDCA-11106) y por la UCEMICH (proyectos UCEMICH-2016-006 y UCEMICH-2017-004). Los autores agradecen al Dr. Iván Medina y al Dr. José Antonio Aguilar por su valiosa ayuda en la revisión del manuscrito.

\section{Literatura citada:}

1. Halasa T, Huijps K, Østerås O, Hogeveen H. Economic effects of bovine mastitis and mastitis management: A review. Vet Q 2007;29(1):18-31.

2. Wenz JR, Barrington GM, Garry FB, Ellis RP, Magnuson RJ. Escherichia coli isolates' serotypes, genotypes, and virulence genes and clinical coliform mastitis severity. J Dairy Sci 2006;89(9):3408-3412.

3. Hagiwara S, Mori K, Okada H, Oikawa S, Nagahata H. Acute Escherichia coli mastitis in dairy cattle: diagnostic parameters associated with poor prognosis. J Vet Med Sci 2014;76(11):1431-1436.

4. Shpigel NY, Elazar S, Rosenshine I. Mammary pathogenic Escherichia coli. Curr Opin Microbiol 2008;11(1):60-65.

5. Blum SE, Heller ED, Sela S, Elad D, Edery N, Leitner G. Genomic and phenomic study of mammary pathogenic Escherichia coli. PLoS ONE 2015;10(9):e0136387.

6. Kempf F, Slugocki C, Blum SE, Leitner G, Germon P. Genomic comparative study of bovine mastitis Escherichia coli. PLoS ONE 2016;11(1):e0147954.

7. Goldstone RJ, Harris S, Smith DG. Genomic content typifying a prevalent clade of bovine mastitis-associated Escherichia coli. Sci Rep 2016;(6):30115.

8. Olson MA, Siebach TW, Griffitts JS, Wilson E, Erickson DL. Genome-wide identification of fitness factors in mastitis-associated Escherichia coli. Applied Environ Microbiol 2018;84(2):e02190-17.

9. Leimbach A, Poehlein A, Vollmers J, Görlich D, Daniel R, Dobrindt U. No evidence for a bovine mastitis Escherichia coli pathotype. BMC Genomics 2017:18(1):359.

10. Clermont O, Bonacorsi S, Bingen E. Rapid and simple determination of the Escherichia coli phylogenetic group. Appl Environ Microbiol 2000;66(10):4555-4558.

11. Suojala L, Pohjanvirta T, Simojoki H, Myllyniemi AL, Pitkälä A, Pelkonen S, Pyörälä S. Phylogeny, virulence factors and antimicrobial susceptibility of Escherichia coli isolated in clinical bovine mastitis. Vet Microbiol 2011;147(3-4):383-388. 
12. Liu Y, Liu G, Liu W, Liu Y, Ali T, Chen W, Yin J, Han B. Phylogenetic group, virulence factors and antimicrobial resistance of Escherichia coli associated with bovine mastitis. Res Microbiol 2014;165(4):273-277.

13. Keane OM. Genetic diversity, the virulence gene profile and antimicrobial resistance of clinical mastitis-associated Escherichia coli. Res Microbiol 2016;167(8):678-684.

14. Dogan B, Rishniw M, Bruant G, Harel J, Schukken YH, Simpson KW. Phylogroup and lpfA influence epithelial invasion by mastitis associated Escherichia coli. Vet Microbiol 2012;159(1-2):163-170.

15. Lippolis JD, Brunelle BW, Reinhardt TA, Sacco RE, Nonnecke BJ, Dogan B, Simpson $\mathrm{K}$, Schukken YH. Proteomic analysis reveals protein expression differences in Escherichia coli strains associated with persistent versus transient mastitis. J Proteomics 2014;(108):373-381.

16. Melchior MB, Vaarkamp H, Fink-Gremmels J. Biofilms: a role in recurrent mastitis infections?. Vet J 2006;171(3):398-407.

17. Atulya M, Mathew AJ, Rao JV, Rao CM. Influence of milk components in establishing biofilm mediated bacterial mastitis infections in cattle: a fractional factorial approach. Res Vet Sci 2014;96(1):25-27.

18. Ramarao N, Nielsen-Leroux C, Lereclus D. The insect Galleria mellonella as a powerful infection model to investigate bacterial pathogenesis. J Vis Exp 2012;(70):e4392.

19. Nathan S. New to Galleria mellonella: modeling an ExPEC infection. Virulence 2014;5(3):371-374.

20. Alghoribi MF, Gibreel TM, Dodgson AR, Beatson SA Upton M. Galleria mellonella infection model demonstrates high lethality of ST69 and ST127 uropathogenic E. coli. PLoS ONE 2014;9(7):e101547.

21. Morgan JK, Ortiz JA, Riordan JT. The role for TolA in enterohemorrhagic Escherichia coli pathogenesis and virulence gene transcription. Microb Pathog 2014;(77):42-52.

22. Ciesielczuk H, Betts J, Phee L, Doumith M, Hope R, Woodford N, Wareham DW. Comparative virulence of urinary and bloodstream isolates of extra-intestinal pathogenic Escherichia coli in a Galleria mellonella model. Virulence 2015;6(2):145-151.

23. Jiménez-Mejía R, Gudiño-Sosa LF, Aguilar-López JA, Loeza-Lara PD. Caracterización molecular de Escherichia coli resistente a antibióticos aislada de mastitis bovina en Michoacán, México. Rev Mex Cienc Pecu 2017;8(4):387-396. 
24. Madico G, Akopyants NS, Berg DE. Arbitrarily primed PCR DNA fingerprinting of Escherichia coli O157: H7 strains by using templates from boiled cultures. J Clin Microbiol 1995;33(6):1534-1536.

25. Stepanović S, Vuković D, Hola V, Bonaventura GD, Djukić S, Ćirković I, Ruzicka F. Quantification of biofilm in microtiter plates: overview of testing conditions and practical recommendations for assessment of biofilm production by staphylococci. APMIS 2007;115(8):891-899.

26. Silva VO, Soares LO, Júnior AS, Mantovani HC, ChangYF, Moreira MAS. Biofilm formation on biotic and abiotic surfaces in the presence of antimicrobials by Escherichia coli isolates from cases of bovine mastitis. Appl Environ Microbiol 2014;80(19):61366145.

27. Wilson K. Preparation of genomic DNA from bacteria. Curr Protoc Mol Biol 2001;56(1):241-245.

28. Mohapatra BR, Broersma K, Mazumder A. Comparison of five rep-PCR genomic fingerprinting methods for differentiation of fecal Escherichia coli from humans, poultry and wild birds. FEMS Microbiol Lett 2007;277(1):98-106.

29. Heras J, Domínguez C, Mata E, Pascual V, Lozano C, Torres C, Zarazaga M. GelJ-a tool for analyzing DNA fingerprint gel images. BMC Bioinformatics 2015;(16):270.

30. Blum SE, Leitner G. Genotyping and virulence factors assessment of bovine mastitis Escherichia coli. Vet Microbiol 2013;163(3-4):305-312.

31. Burvenich C, Van Merris V, Mehrzad J, Diez-Fraile A, Duchateau L. Severity of E. coli mastitis is mainly determined by cow factors. Vet Res 2003;34(5):521-564.

32. Ghanbarpour R, Oswald E. Phylogenetic distribution of virulence genes in Escherichia coli isolated from bovine mastitis in Iran. Res Vet Sci 2010;88(1):6-10.

33. Milanov D, Prunić B, Velhner M, Todorović D, Polaček V. Investigation of biofilm formation and phylogenetic typing of Escherichia coli strains isolated from milk of cows with mastitis. Acta Veterinaria 2015;65(2):202-216.

34. Dogan B, Klaessig S, Rishniw M, Almeida RA, Oliver SP, Simpson K, Schukken YH. Adherent and invasive Escherichia coli are associated with persistent bovine mastitis. Vet Microbiol 2006;116(4):270-282.

35. Moser A, Stephan R, Corti S, Lehner A. Resistance profiles and genetic diversity of Escherichia coli strains isolated from acute bovine mastitis. Schweiz Arch Tierheilkd 2013;155(6):351-357. 
36. Fernandes JBC, Zanardo LG, Galvão NN, Carvalho IA, Nero LA, Moreira MAS. Escherichia coli from clinical mastitis: serotypes and virulence factors. J Vet Diagn Invest 2011;23(6):1146-1152.

37. Flemming HC, Wingender J, Szewzyk U, Steinberg P, Rice SA, Kjelleberg S. Biofilms: an emergent form of bacterial life. Nat Rev Microbiol 2016;14(9):563-575.

38. Naves P, Del Prado G, Huelves L, Gracia M, Ruiz V, Blanco J, Rodríguez-Cerrato V, Ponte MC, Soriano F. Measurement of biofilm formation by clinical isolates of Escherichia coli is method- dependent. J Appl Microbiol 2008;105(2): 585-590. 